\title{
中国産ガムテレビン油中の高沸点部成分
}

\author{
笠 野 雅 信*・松 原 義 治* \\ * 近畿大学理工学部応用化学科 (東大阪市小若江 3-4-1)
}

\section{High-boiling Constituents of China Gum Terpentine}

\author{
Masanobu Kasano* and Yoshiharu Matsubara* \\ * Department of Applied Chemistry, Faculty of Science and Technology, \\ Kinki University (Kowakae Higashiosaka-shi)
}

\begin{abstract}
High-boiling fractions of China gum terpentine have been investigated. The following compounds were shown to be present; $\alpha$-longipinene longicyclene, $\beta$-ylangene, longifolene, $\beta$-caryophyllene, $\alpha$-hu $=$ mulene, $\beta$-humulene, $\delta$-cadinene, $\gamma$-cadinene, calamenene, dihydrocaryophyllene- 5 -one, longi- $\beta$-fenchyl $=$ alcohol, caryophylla-4 (12), 8 (13)-dien-5 $\alpha$-ol, caryophylla-3,8 (13)-dien-5 $\alpha$-ol, and caryophylla-3,8 (13)-dien-5 $\beta$-ol.
\end{abstract}

\section{1 緒言}

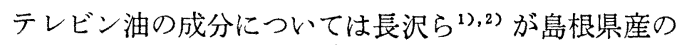
テレビン油モノテルペン成分について検討し報告してい る。しかし現在生産されている天然精油中けた外れに生 産量の大きいテレビン油の高沸点成分について, 最近, ほとんど検討されていない。

著者らはファインケミカルズ合成原料として特に重要 であり，貴重な天然資源であるテレビン油の成分を明確 にし, 有効な利用途を換起する目的で中国産ガムテレビ ン油中の高沸点部成分について検討した。

高沸点部のうちセスキテルペン炭化水素部沈いては $20 \%$ も存在する $\beta$-カリオフィレンをはじめ 10 成分す心゙ てを確認した。またセスキテルペンアルコール及びオキ ソ化合物の検出に当たっては, 生合成経路から考え, 含 有するセスキテルペン炭化水素が酸化された生成物の存 在を予見して，まずセスキテルパン炭化水素部中，主成 分として含有しているロンギホレン, $\beta$-カリオフィレン の稳やかな酸化反応生成物 (四酶酸鉛酸化生成物 ${ }^{3), 4}$ 及 びクロロ置換酢酸による水和反応生成物 ${ }^{(5,6)}$ ) の MS ス ペクトルを測定し，それらと中国産テレビン油高沸点部 セスキテルペンアルコール及びオキソ体部の MS スペ クトルと同定される 5 種の成分の存在を認めた。今回著 者らが存在を認めた 5 種の成分については正確を期する ため GLC 分取し, IR, NMR スペクトルを測定したと ころそれぞれ既知標品と同定された。

\section{2 実験}

\section{$2 \cdot 1$ 試料の調製}

中国産ガムテレビン油高沸点部堂蒸留によりセスキテ ルペン炭化水素部（bp $94^{\circ} \mathrm{C} / 2 \mathrm{mmHg}$ ) とセスキテルペ ンアルコール及びオキソ体部 (bp $120 \sim 130^{\circ} \mathrm{C} / 1 \mathrm{mmHg}$ ) に分離した。セスキテルペン炭化水素部门うち主成分 （1)，(4) 及び（5）についてはマクマホン式精留塔で減 圧下精留により単離し, 微量成分については精留で含有 量を上げたのち分取 GLC(PEG 6000, $4 \mathrm{~m}$ ，カラム温度 $150^{\circ} \mathrm{C}$ ，キャリヤーガス $\mathrm{H}_{2} 1 \mathrm{~kg} / \mathrm{cm}^{2}$ ) で分離した。

\section{$2 \cdot 2$ 機器分析}

IR は $\mathrm{KBr}$, 日本分光-IRA-2 型-回折格子赤外分光光 度計, NMR は日立-Perkin-Elmer R-20 B 型, MS は 加速電圧 $3500 \mathrm{~V}$ ，イオン化電圧 $20 \mathrm{eV}$, 島津 LKB 9000 ガスクロマトグラフィー一質量分析計を使用した。

$2 \cdot 3$ ジヒドロカリオフィレン-5-オン (19)

$\mathrm{MS}(\mathrm{m} / \mathrm{e}) ; 220(8), 205(12), 123(44), 121(62), 110$ (44), 109(72), 107(76), 106(48), 105 (48), 96(46), 95(80), 94(40), 93(100), 91(48), 83(34), 82(40), 81(56), 79(76), 69(68)

IR $\left(\mathrm{cm}^{-1}\right) ; 1716(\mathrm{C}=\mathrm{O}), 3075,1635,894\left(=\mathrm{CH}_{2}\right)$, $1380,1365\left(\mathrm{C}\left(\mathrm{CH}_{3}\right)_{2}\right)$

$\operatorname{NMR}\left(\delta_{\mathrm{ppm}}^{\mathrm{CDCl}_{3}}\right) ; 0.99\left(s, 6 \mathrm{H}, \mathrm{C}\left(\mathrm{CH}_{3}\right)_{2}\right), 1.13(d, 3 \mathrm{H}$, $\mathrm{CH}_{3}, \mathrm{~J}=3 \mathrm{H}_{2}$ ), 4.81, 4.91(two $s$, $2 \mathrm{H},=\mathrm{CH}_{2}$ )

$2 \cdot 4$ ロンギ- $\beta$-フェンチルアルコール（26） $\mathrm{mp} 81 \sim 82^{\circ} \mathrm{C}$

MS $(m / e) ; 222(9), 207(49), 204(48), 189(38), 119$ (66), 109(62), 107(40), 95(91), 85(100), 81(37), 69(31) 
IR $\left(\mathrm{cm}^{-1}\right) ; 3380,1042(\mathrm{OH}), 1380,1365\left(\mathrm{C}\left(\mathrm{CH}_{3}\right)_{2}\right)$ $\operatorname{NMR}\left(\delta_{\mathrm{ppm}^{2}}^{\mathrm{CDCl} \mathrm{Cl}_{3}}\right) ; 0.82\left(s, 3 \mathrm{H}, \mathrm{CH}_{3}\right), 0.85(s, 3 \mathrm{H}$, $\left.\mathrm{CH}_{3}\right), 0.91\left(s, 6 \mathrm{H}, \mathrm{CH}_{3} \times 2\right), 1.43$ (br. $s, 1 \mathrm{H}, \mathrm{OH}), 1.80 \sim 2.10(\mathrm{~m}$, $\left.1 \mathrm{H},>\mathrm{CH}^{-}\right), 3.68 \sim 3.81(m, 1 \mathrm{H}$, $\mathrm{CHOH})$

$2 \cdot 5$ カリオフィラ-4(12), 8 (13)-ジエン-5 $\alpha$-オール (31)

$\operatorname{MS}(m / e) ; 220(7), 205(10), 158(20), 148(23), 136$ (100), 135(28), 131(27), 121(23), 109 (27), 107(30), 93(30), 91(30), 81(23), $69(32)$

IR $\left(\mathrm{cm}^{-1}\right) ; 3350(\mathrm{OH}), 3065,1638,1630,885\left(=\mathrm{CH}_{2}\right)$ $\operatorname{NMR}\left(\delta_{\mathrm{ppm}^{2}}^{\mathrm{CDCl}_{3}}\right) ; 1.00\left(s, 6 \mathrm{H}, \quad \mathrm{C}\left(\mathrm{CH}_{3}\right)_{2}\right), \quad 1.85(s$, $1 \mathrm{H}, \mathrm{OH}), 3.85 \sim 4.09(m, 1 \mathrm{H}, \mathrm{CH}$ $\mathrm{OH}), 4.69\left(s, 2 \mathrm{H},=\mathrm{CH}_{2}\right), 4.85$, $4.96\left(m, 2 \mathrm{H},=\mathrm{CH}_{2}\right)$

2.6 カリオフィラ-3, 8(13)-ジエン-5 a-オール (32) $\operatorname{MS}(m / e) ; 220(10), 205(15), 202(18), 187(49)$, $149(46), \quad 135(51), 133(49), 131(67)$, 123(85), 121(51), 109(67), 107(80), 105(62), 95(62), 93(100), 91(51), 81 (82), 79(46), 69(44)

$\operatorname{IR}\left(\mathrm{cm}^{-1}\right) ; 3400(\mathrm{OH}), 3070,1635,892\left(=\mathrm{CH}_{2}\right), 1385$, $1368\left(\mathrm{C}\left(\mathrm{CH}_{3}\right)_{2}\right)$

$\operatorname{NMR}\left(\delta_{\mathrm{ppm}}^{\mathrm{CDCl}_{3}}\right) ; 0.98\left(s, 3 \mathrm{H}, \mathrm{CH}_{3}\right), 1.01(s, 3 \mathrm{H}$, $\left.\mathrm{CH}_{3}\right), 1.63\left(s, 3 \mathrm{H}, \mathrm{CH}_{3}\right), 4.78(s$, $\left.2 \mathrm{H}, \quad=\mathrm{CH}_{2}\right), \quad 4.85 \sim 499(m, 1 \mathrm{H}$, $\mathrm{CHOH}), 5.18 \sim 5.61(m, 1 \mathrm{H},-\mathrm{CH}=)$

$2 \cdot 7$ カリオフィラ-3,8(13)-ジエン-5 $\beta$-オール (33) MS (m/e); 220(12)，205(21)，202(24)，159(44), $149(71), \quad 146(41), 135(62), 133(50)$, 131(82), 123(59), 121(71), 119(42), $109(88), \quad 108(53), \quad 107(94), \quad 106(41)$, 105(77), 95(71), 93(100), 92(71), 91 (62), 81(71), 79(56), 69(50)

IR $\left(\mathrm{cm}^{-1}\right) ; 3350(\mathrm{OH}), 1639,895\left(=\mathrm{CH}_{2}\right)$ $\operatorname{NMR}\left(\delta_{\mathrm{ppm}^{2}}^{\mathrm{CDCl}_{3}}\right) ; 0.98\left(s, 3 \mathrm{H}, \mathrm{CH}_{3}\right), 1.03(s, 3 \mathrm{H}$, $\left.\mathrm{CH}_{3}\right), 1.60\left(s, 3 \mathrm{H}, \mathrm{CH}_{3}\right), 4.50 \sim$ $4.84(m, 1 \mathrm{H}, \mathrm{CHOH}), 4.42,4.67$ $\left(m, 2 \mathrm{H},=\mathrm{CH}_{2}\right), 5.45(t, 1 \mathrm{H},-\mathrm{CH}=$, $\mathrm{J}=7.5 \mathrm{H}_{2}$ )

\section{3 結果及び考察}

試料とした中国産ガムテレビン油はアルカリ処理を行 いフェノール部とカルボン酸部を除去して得られる中性
部からモノテルペン部を蒸留で除去して得られる高沸点 部を減圧下精留して，セスキテルペン炭化水素部上セス キテルペンアルコール及びオキソ体部に分離した。高沸 点部の 5ち $65 \%$ を占めるセスキテルペン炭化水素部の ガスクロマトグラムは Fig.-1 に示した通りである。セ スキテルペン炭化水素部の主成分（1)，(4) 及び（5）は

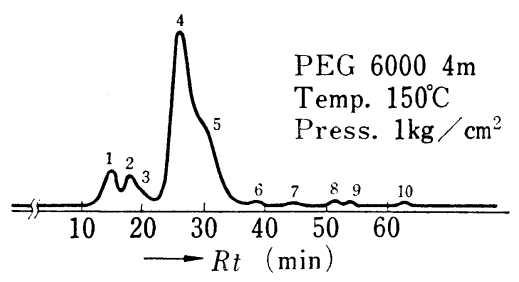

Fig.-1 Gaschromatogram of sesquiterpene hydrocarbon part.

マクマホン式精留塔で減圧下精留により単離し, 微量成 分は精留で含有量を上げたのち GLC で分取し，既知標 品の IR, NMR, MS スペクトルと比較してそれらの構 造を決定した。その結果は Table-1 に示した。

Table-1 Components of sesquiterpene hydrocarbon part.

\begin{tabular}{r|l|r|l}
\hline No & Compound & $\%$ & $\begin{array}{l}\text { Method of } \\
\text { identification }\end{array}$ \\
\hline 1 & $\alpha$-Longipenene & 8 & IR, NMR, MS \\
2 & Longicyclene & 4 & IR, NMR, MS \\
3 & $\beta$-Ylangene & 3 & IR, NMR, MS \\
4 & Longifolene & 65 & IR, NMR, MS \\
5 & $\beta$-Caryophyllene & 20 & IR, NMR, MS \\
6 & $\alpha$-Humulene & Tr. & IR, NMR, MS \\
7 & $\beta$-Humulene & Tr. & IR, NMR, MS \\
8 & $\delta$-Cadinene & Tr. & GLC, MS \\
9 & $\gamma$-Cadinene & Tr. & GLC, MS \\
10 & Calamenene & Tr. & GLC, MS \\
\hline
\end{tabular}

Fig.-2 にセスキテルペンアルコール及びオキソ化合 物部のガスクロマトグラムを示した。ガスクロマトグラ ムには (11)〜(33) の 23 本のピークが恋められ, 各成 分の MS スペクトルを測定し, その MS スペクトルと ロンギホレン， $\beta$ 一カリオフィレンの四酢酸鈆酸化及びク 口ロ置換酶酸による水和反応で得た反応生成物の MS ス ペクトルとを比較した。その結果，23 成分中 5 成分の みを確認した（Table-2）。(19)の MS スペクトルはßカリオフィレンの四酶酸鉛酸化 ${ }^{4)}$ で得たジヒドロカリオ フィレン-5-オンと同定された。またその IR, NMR ス ペクトルは $\beta$-カリオフィレンの四酢酸鈆酸化で得た化 合物のそれらと一致したことからジヒドロカリオフィレ ン-5-オン (19) と確認した。

(26) の MS スペクトルには M+222 が認的られる。 


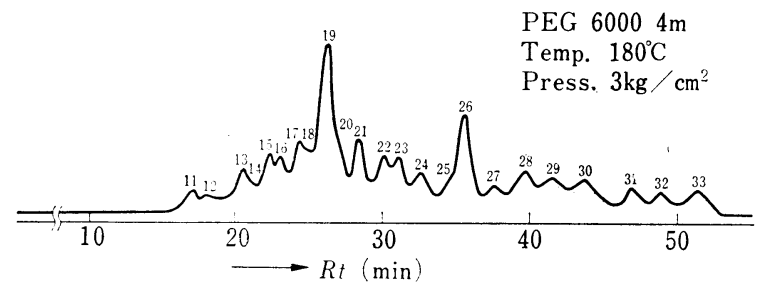

Fig.-2 Gaschromatogram of sesquiterpene alcohol and ketone part.
1.43$, br. $s),>\mathrm{CH}-(\delta 1.80 \sim 2.00, m)$, $\mathrm{CHOH}(\delta 3.68 \sim 3.81, m)$ が見受けられ る。また $\mathrm{C}_{(3)}$ 位の立体化学を明らかにす るため $\mathrm{Eu}(\mathrm{dpm})_{3}$ によるコンタクトシフ 卜を測定した (Table-3)。その結果, $\mathrm{C}_{(7)}$ $-\mathrm{CH}_{3}$ と $\mathrm{C}_{(2)}-\mathrm{CH}_{3}$ のコンタクトシフトの 比較より $\mathrm{C}_{(7)}-\mathrm{CH}_{3}$ の方が $\mathrm{C}_{(2)}-\mathrm{CH}_{3}$ より $\mathrm{OH}$ と近距離にあることが判明した。また $\mathrm{C}_{(4)}-\mathrm{CH}_{2}$ が $\mathrm{OH}$ とかなり近距離にあるこ ともわかった。これらの事実を考慮し，分 子モデルの解析を行い $\mathrm{OH}$ が $\beta$-配置であ

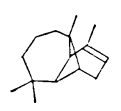

(1)

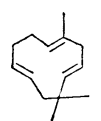

(6)

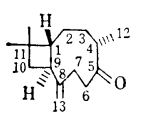

(19)

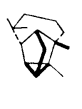

(2)
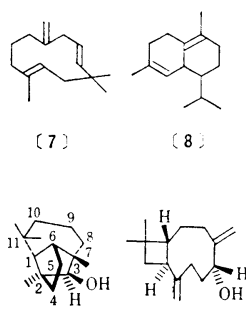

(26)
$(8)$

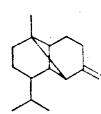

(3)

(31)

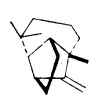

(4)

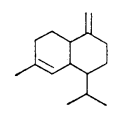

(9)

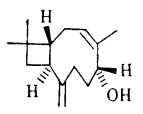

(32)

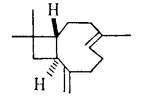

(5)

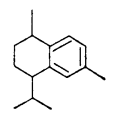

(10)

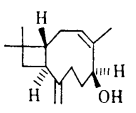

(33)
Fig.-3

そのほかのフラグメントイオンもすべて田中ら゙5がロン ギホレンの水和反応で単離, 構造決定したロンギフェン チルアルコールと同定される。IR スペクトルには $\mathrm{OH}, \mathrm{C}$ $\left(\mathrm{CH}_{3}\right)_{2}$ の吸収が見られ，NMR スペクトルには $\mathrm{CH}_{3}(\delta$ $0.82, s), \mathrm{CH}_{3}(\delta 0.85, s), \mathrm{CH}_{3} \times 2(\delta 0.91, s), \mathrm{OH}(\delta$
ることを認めた。

(31) の MS スペクトルは $\beta$-カリオフィレンの四酢 酸鉛酸化で得たカリオフィラ-4(12), 8(13)-ジェン-5 $\alpha-$ オールと同定された。その IR 及び NMR スペクトル も B-カリオフィレンの四酢酸鉛酸化で得た化合物のそ れらと一致したことからカリオフィラー4(12), 8(13)-ジ

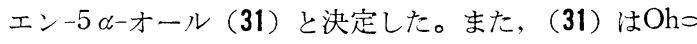

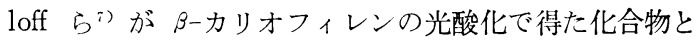
同定され，林ら ${ }^{8)}$ が若狭湾及び山陰海岸に主として分布 しているわかさはまぎくの精油から単離し，Wakasaこ enseol と命名している。

（32）及び（33）の MS スペクトルも $\beta$-カリオフィ レンの四酶酸鈆酸化で 得たカリオフィラ-3, 8(13)-ジェ ン-5 $\alpha$-オール及びカリオフィラ-3, 8 (13)-ジエン $-5 \beta-$ オールと同定された。またその IR 及び NMR スペク トルもそれぞれ $\beta$-カリオフィレンの四酶酸鉛酸化で得 た化合物と完全に一致したことから（32）はカリオフィ ラ-3,8(13)-ジェン-5 $\alpha$-オール (32)，(33）はカリオフ ィラ-3, 8(13)-ジェン-5 $\beta$-オール（33）であると決定し た。

Table-2 Components of sesquiterpene alcohol and ketone.

\begin{tabular}{|c|c|c|c|c|c|}
\hline No & Compound & $\begin{array}{l}\text { Method of } \\
\text { identification }\end{array}$ & No & Compound & $\begin{array}{l}\text { Method of } \\
\text { identification }\end{array}$ \\
\hline 11 & Unknown & - & 23 & Unidentify $\left(\mathrm{M}^{+} 230\right)$ & MS \\
\hline 12 & Unknown & - & 24 & Unidentify $\left(\mathrm{M}^{+} 272\right)$ & MS \\
\hline 13 & Unidentify $\left(\mathrm{M}^{+} 220\right)$ & MS & 25 & Unknown & - \\
\hline 14 & Unidentify $\left(\mathrm{M}^{+} 220\right)$ & MS & 26 & Longi- $\beta$-fenchylalcohol & MS, IR, NMR \\
\hline 15 & Unidentify $\left(\mathrm{M}^{+} 220\right)$ & MS & 27 & Unknown & - \\
\hline 16 & Unidentify $\left(\mathrm{M}^{+} 220\right)$ & MS & 28 & Unidentify $\left(\mathrm{M}^{+} 230\right)$ & MS \\
\hline 17 & Unidentify $\left(\mathrm{M}^{+} 220\right)$ & MS & 29 & Unidentify $\left(\mathrm{M}^{+} 220\right)$ & MS \\
\hline 18 & Unknown & - & 30 & Unidentify $\left(\mathrm{M}^{+} 220\right)$ & MS \\
\hline 19 & Dihydrocaryophyllene-5-one & MS, IR, NMR & 31 & $\begin{array}{l}\text { Caryophylla-4(12), } \\
8(13)-\text { dien-5 } \alpha-\text { ol }\end{array}$ & MS, IR, NMR \\
\hline 20 & Unknown & - & 32 & $\begin{array}{l}\text { Caryophylla-3, 8(13) } \\
- \text { dien }-5 \alpha \text {-ol }\end{array}$ & MS, IR, NMR \\
\hline 21 & Unidentify $\left(\mathrm{M}^{+} 220\right)$ & MS & 33 & $\begin{array}{l}\text { Caryophylla-3,8(13) } \\
- \text { dien-5 } \beta-\text { ol }\end{array}$ & MS, IR, NMR \\
\hline 22 & Unidentify $\left(\mathrm{M}^{+} 220\right)$ & MS & & & \\
\hline
\end{tabular}

* $\mathrm{M}^{+} 220$ and 222 are sesquiterpene alcohol or ketone 
Table-3 Variation in the chemical shift for different protons of (26) $\left(1 \times 10^{-4} \mathrm{~mol}\right.$. in $0.5 \mathrm{ml}$ of $\mathrm{CDCl}_{8}$ ) with increasing concentration of $\mathrm{Eu}(\mathrm{dpm})_{3}$.

\begin{tabular}{|c|c|c|c|c|c|c|c|}
\hline \multirow{2}{*}{$\begin{array}{l}\mathrm{Eu}(\mathrm{dpm})_{3} \\
\times 10^{-4}(\mathrm{~mol})\end{array}$} & \multicolumn{7}{|c|}{$\delta \operatorname{ppm}\left(\Delta \mathrm{Eu}(\mathrm{dpm})_{3}\right)^{\mathrm{a})}$} \\
\hline & ${ }^{c}(11)^{-\mathrm{CH}_{8}}$ & ${ }^{\mathrm{c}}(11)^{-\mathrm{CH}_{8}}$ & $\mathrm{c}(2)^{-\mathrm{CH}_{3}}$ & $\mathrm{c}(7)^{-\mathrm{CH}_{3}}$ & $\mathrm{c}(3)^{-\mathrm{H}}$ & $\mathrm{c}_{(4)^{-\mathrm{H}}}$ & $\mathrm{C}(4)^{-\mathrm{H}}$ \\
\hline 0 & 0.82 & 0.85 & 0.91 & 0.91 & 3.74 & - & - \\
\hline 0.11 & $0.98(0.16)$ & $1.05(0.20)$ & $1.48(0.57)$ & $1.53(0.62)$ & $4.76(1.02)$ & - & - \\
\hline 0.21 & $1.24(0.42)$ & $1.32(0.47)$ & $2.04(1.13)$ & $2.16(1.25)$ & $6.52(2.78)$ & - & - \\
\hline 0.30 & $1.50(0.68)$ & $1.56(0.71)$ & $2.61(1.70)$ & $2.78(1.87)$ & $8.13(4.39)$ & 3.87 & 4.77 \\
\hline 0.41 & $1.72(0.90)$ & $1.79(0.94)$ & $3.15(2.24)$ & $3.41(2.50)$ & $9.62(5.88)$ & 4.87 & 5.89 \\
\hline 0.52 & $1.99(1.17)$ & $2.01(1.16)$ & $3.71(2.80)$ & $4.04(3.13)$ & $11.39(7.65)$ & 6.06 & 7.10 \\
\hline 0.62 & $2.27(1.45)$ & $2.27(1.42)$ & $4.28(3.37)$ & $4.63(3.72)$ & $12.99(9.25)$ & 7.17 & 8.23 \\
\hline 0.71 & $2.50(1.68)$ & $2.51(1.66)$ & $4.83(3.92)$ & $5.28(4.37)$ & $14.83(11.09)$ & 8.32 & 9.41 \\
\hline
\end{tabular}

a) $\triangle \mathrm{Eu}(\mathrm{dpm})_{3} ; \delta \mathrm{Eu}(\mathrm{dpm})_{3}-\delta \mathrm{CDCl}_{3}$

以上, 中国産ガムテレビン油高沸点部から 10 種のセ スキテルペン炭化水素と 5 種のセスキテルペンアルコー ル及びケトン体を単離した。

1977 年 11 月, 第 21 回香料, テルペン及び精油化学に関す る討論会講演

(昭和 52 年 11 月 28 日受理)

$$
\text { 文献 }
$$

1) 長沢 徹, 城代 進, 香料, 62 号, 53 (1961)

2) 長沢 徹, 城代 進, 香料, 63 号, 45 (1961)
3）笠野雅信, 松原義治, 油化学, 27, 309 (1978)

4）笠野雅信，松原義治，日化投稿中，“ $\beta$-カリオフィレンの 四酢酸鉛酸化”

5）田中清文，湯川代代樹，松原義治，日化，1976，1247

6）田中清文，松原義治，日化，1976,1883

7) K.H. Schulte-Elte, G. Ohloff, Helv. Chim. Acta, 51, 494 (1968)

8）島崎俊一, 内尾康人, 松尾昭彦, 中山 充, 林 修一, 香料, テルペンおよび精油化学に関する討論会講演要旨 集, 19，116 (1975) 